\title{
A LITERATURA NO CONTEXTO ESCOLAR E A FORMAÇÃO DE LEITORES
}

\section{ARTIGO ORIGINAL}

RICARDO, Fátima Sueli Vidoto ${ }^{1}$

NEVES, Rejane Melo da Silva ${ }^{2}$

RICARDO, Fátima Sueli Vidoto. NEVES, Rejane Melo da Silva. A literatura no contexto escolar e a formação de leitores. Revista Científica Multidisciplinar Núcleo do Conhecimento. Ano 05, Ed. 08, Vol. 06, pp. 37-46. Agosto de 2020. ISSN: 24480959, Link de acesso: https://www.nucleodoconhecimento.com.br/letras/literatura-nocontexto

\section{RESUMO}

Este trabalho se trata sobre a reflexão em relação as contribuições da leitura para a formação de alunos nos anos iniciais. Abordando a importância de criar um hábito de leitura desde a alfabetização, apresenta também, o papel do professor quanto ao incentivo da leitura e à formação de novos leitores. A partir de uma fundamentação teórica, propõe uma análise acerca da função da leitura em vários aspectos, mostrando assim, a necessidade de incentivar a prática da leitura em toda a sociedade. A pesquisa para este estudo foi integralmente teórica, consultando-se alguns autores sobre o tema. Ao se pensar em leitura, pensa-se, também, na escrita, pois esses passos são primordiais ao desempenho do aluno na escola. Contudo, tal

\footnotetext{
${ }_{1}$ Pós graduada em língua portuguesa e literatura, Graduação: Letras, pós graduada em Educação musical aplicada à educação básica. e Educação especial inclusiva à educação básica. Graduação: Pedagogia.

${ }^{2}$ Graduada em Pedagogia da Universidade Nove de Julho, (UNINOVE) de São Paulo; Licenciada em Língua Portuguesa e literatura (Letras) na Faculdade Integrada de Naviraí MS (FINAV).
} 
prática deve ser prazerosa, tranquila e significante para que o aluno tenha a possibilidade de adquirir conhecimentos com qualidade. Por isso, há a necessidade de se fazer reflexões referentes ao tema leitura, pois ele promove habilidades, saberes novos e oportunidades de ampliação da visão de mundo.

Palavras-chave: Leitura, leitores, aprendizagem.

\section{INTRODUÇÃO}

A leitura é algo muito importante, tanto para educadores quanto para educandos e, também, para a sociedade em geral, contribuindo para que todos tenham uma noção mais crítica de mundo. Esta faz com que as pessoas possam se comunicar, aprender e entender o mundo do qual fazem parte. Este trabalho procura evidenciar a ideia de que a leitura não visa, apenas, a decodificação de um texto, mas sim dos sons, imagens e gestos, como definido por Paulo Freire: a leitura do nosso mundo vem antes da leitura das palavras (FREIRE, 1988). A família e a escola são elementos que possuem grande influência na formação de novos leitores. Dessa forma, o contato dos educandos com os mais diversos textos, orais ou escritos, principalmente os textos literários, tema da presente investigação, depende do incentivo da família e da escola.

Para o autor Cosson (2006), a literatura possui a função de humanização do indivíduo. Assim, este trabalho visa analisar a presença da literatura nas salas de aula do Ensino Fundamental, seja em casa ou na escola, com incentivo dos professores e pais. Segundo Maia (2007, p. 60), "quanto mais antecipadamente a criança convive com a presença de livros e a literatura, mais terá um futuro como leitor". A literatura se transforma em um bem cultural e, com isso, as pessoas entram em contato com tempos passados, com o presente e até com o futuro.

De acordo com Oliveira (2010), a literatura recorrentemente produz conhecimento, pois nada mais é que, a releitura do passado, nos possibilitando realizar comparações com o presente, a fim de analisar os acontecimentos e os modos de vida. Essa afirmação do autor é muito importante, pois demonstra-se que é a partir do 
conhecimento do passado e das histórias do presente que todos podem ter um melhor entendimento de mundo e de si próprio.

O presente trabalho se justifica pela necessidade de entender e refletir sobre a literatura no Ensino Fundamental, a prática literária na escola e compreender a leitura como meio de conhecimento e como transmissora de ideias. Visa, também, investigar como se formam leitores a partir de estratégias e processos educativos que estimulam a leitura. Além de tudo, este estudo espera entender o importante papel do professor na construção do novo leitor e sua atuação ao estimular a leitura de vários gêneros literários trazendo progressos aos leitores.

\section{METODOLOGIA}

Propõe-se uma pesquisa bibliográfica e qualitativa utilizando referências teóricas que compreendem visões múltiplas dos autores sobre o tema. Como parte do desenvolvimento deste trabalho, o assunto será desmembrado em tópicos. O primeiro deles é uma introdução que resume o tema e os objetivos do presente estudo; o segundo aborda os leitores em formação, ou seja, os alunos do Ensino Fundamental. O terceiro capítulo, por fim, recupera ideias tangentes ao perfil e à função do educador na introdução da leitura. O professor precisa estar atento aos novos recursos que possam despertar, nos alunos, um maior interesse pela leitura.

\section{FUNDAMENTAÇÃO TEÓRICA}

Para que haja a formação de leitores no Ensino Fundamental, conforme indica Cosson (2006), é preciso fazer uma comparação, isto é, deve-se comparar o aspecto intelectual com o físico. Dessa forma, é possível exercitar o corpo intelectual para que ele não atrofie com o passar do tempo. É preciso que a leitura esteja presente no dia a dia, e, desse modo, quanto mais é praticada, mais permanece saudável. Quanto mais se lê, melhor e maior será sua leitura e seu repertório. Na percepção de Cosson (2006), todas as pessoas ao serem submetidas, ambientadas e/ou desafiadas com leituras complexas, acabam se tronando leitores e desenvolvendo a prática da leitura. 
Por isso, é necessário mediação para que o aluno possa se aprofundar na leitura. No ambiente escolar, o educador é aquele que faz a mediação entre o livro e o leitor.

Cosson (2006, p. 38) assegura que: "a leitura não é apenas uma letra impressa numa folha de papel. Astrólogos podem ler as estrelas ao tentar prever o futuro. Um músico precisa ler as partituras para poder executar uma sonata". A literatura, conceituada pelo autor Candido (1995), tem a função de desenvolver e formar personalidades que se acoplam a realidade do aluno. Maia (2007) afirma que, a formação de um leitor crítico necessita de um professor engajado, que tenha uma visão crítica, para que a literatura tenha função formadora e que não se restrinja a uma missão, apenas no âmbito pedagógico. Mas não é somente a escola ou o professor que precisam incentivar a leitura, o ambiente familiar também tem a sua responsabilidade no que se refere a formação do novo leitor.

Conforme Maia:

Mesmo com a ênfase existente na escola na função de formar leitores, uma outra instituição também pode e deve contribuir, que é à família. Um leitor é formado até mais ou menos aos doze anos de idade segundo a UNESCO - Organização de Nações Unidas para Educação, ciência e Cultura, sendo assim fundamental que uma criança possa ter contato com livros já nos primeiros anos de sua vida (MAIA, 2007, p. 51).

Fica claro que o ambiente escolar e o familiar possuem um grande poder transformador nos alunos no que tange o incentivo ao contato com a literatura que, segundo Cosson (2006), é um processo que demanda interconexões, que contribuem na formação cultural do indivíduo durante o processo de aprendizagem e contato com a leitura e escrita. Nesse sentido ${ }_{2}$ Azevedo informa que:

Poucas são as crianças que interagem com adultos, sejam pais ou professores que incentivam a leitura, comentam sobre livros ou autores. Até mesmo os livros dito clássicos, pois na realidade eles não são leitores e também não se interessam por literatura. Por mais bem intencionados que essas pessoas sejam, elas tem uma ideia de literatura um pouco idealizadora demais, apenas como sendo algo mágico, indescritível, referindo-se como sendo uma viagem e coisas desse tipo (AZEVEDO, 2004, p. 38). 
Somente o estímulo, sem exemplos e atitudes, não é um incentivo e isso cabe, também, ao professor: se ele não é, de fato, um leitor, seus alunos provavelmente também não serão. Como o autor Lajolo assegura "alunos não leem, professores também; alunos escrevem muito mal e professores também" (apud LAJOLO, 2011, p. 300). Resumindo, se os educadores não gostam do que fazem, alunos também não irão gostar. A ação de ler não significa somente decodificar, pois, muitos alunos, não possuem muita noção do que seria interpretar um texto. Segundo Cosson (2006, p. 39), "a leitura é compreendida como se fosse um processo para decodificar, e apenas ênfase o código que está no texto é levado em conta". Conforme Kleimam (1997), o processo do ensino de leitura conscientiza o aluno de qual é a intenção, quais são as mensagens que o autor do texto deseja evidenciar.

O educador deve orientar seus alunos no momento da leitura, compreender os conhecimentos que o aluno já traz e levar de encontro ao texto. É importante para a total formação de um leitor, o incentivo de pais e educadores. O gosto pela leitura será construído quando houver uma interação entre a família e a escola. Sem o incentivo destas instituições, não é possível a formação de um aluno leitor, principalmente no que diz respeito aos textos literários. Sobre a formação dos professores, a Lei de Diretrizes e Base da Educação Nacional, Lei 9.394/1996 preconiza que se deve adotar um modelo que se encontra materializado nos Parâmetros Curriculares Nacionais (PCNs/1998).

O parágrafo único do Art. 61 da LDB 9.394/96, alterado pela lei 12.014/2009, dispõe sobre a formação dos profissionais da educação e, em seu inciso I, afirma que a formação do professor terá, como fundamento: "a presença de sólida formação básica, que propicie o conhecimento dos fundamentos científicos e sociais de suas competências de trabalho". A indagação que fica é se os professores têm conhecimentos científicos necessários para o ensino da leitura. Nos Parâmetros Curriculares Nacionais (PCNs) podemos visualizar que há uma atenção maior ao tipo de cidadão que se pretende formar na escola. Também se observa como as habilidades do professor, no que tange a sua atuação docente, valorizam o ensino interdisciplinar e enfocam a necessidade de novas práticas pedagógicas. 
Nesse sentido, é papel do professor fomentar espaços que enfoquem a participação e a reflexão, de forma a promover, aos discentes, a harmonia no que tange as mudanças e incertezas do meio social, pois repercutem no contexto escolar. A leitura é a ferramenta mais capaz de sustentar a consolidação do conhecimento nos mais diversos contextos, e, assim, a sua prática é urgente. Cabe auferir que, atualmente, os docentes se deparam com certas limitações tangentes à sua formação que os impedem de aperfeiçoar a sua prática pedagógica em sala de aula. Para Kleiman (2001), esse problema, usualmente, recai sobre os docentes de língua portuguesa. Ressalta, também, que a eficácia do ensino-aprendizagem depende da inovação docente e, ainda, da vontade do aluno em aprender e mudar os seus hábitos.

Kleiman (2001) frisa, também, que é o professor quem organiza as práticas educativas, e, desse modo, o sucesso ou fracasso do contato do aluno com a leitura está relacionado à tais práticas. É preciso, portanto, refletir sobre a formação leitora tanto dos alunos quanto dos próprios docentes, pois, a maioria desses profissionais, possuem pouco ou nenhum contato com a leitura. Deve-se considerá-la como uma prática educativa, e, para que possa ser empregada de modo eficiente, é preciso considerar que é na relação leitor-autor que o texto ganha sentido. A partir da compreensão que o discente se identifica e atribui os seus conhecimentos de mundo ao texto lido, o que os aproxima e instiga a procurar mais sobre textos que reflitam a sua realidade.

Para Kleiman (1989), compreender um texto é uma atividade que demanda certo conhecimento anterior, pois o leitor procura nos textos por aquilo que já sabe, ou seja, pelo conhecimento que adquiriu durante a sua trajetória de vida. A partir desse processo o aluno interagem com diversos tipos de conhecimento: o linguístico, o textual, o de mundo. É nessa relação que o sentido de um texto é construído. O leitor analisa, então, como esses conhecimentos interagem entre si e é por esse motivo que a leitura é tida como um ato típico da interação humana. As reflexões de Dalvi (2011) apontam que muitos licenciados em Letras se sentem inseguros no que tange a própria formação e competência para o exercício da docência. É o conhecimento 
técnico, prático e reflexivo da docência que inova a prática pedagógica e metodológica.

É a inovação que acarreta novas práticas docentes. Cabe, portanto, ao contexto universitário, a promoção da formação, também, em leitura, pois apenas dessa forma estarão aptos para promover o contato dos alunos com a leitura. Existe uma ausência de programas de formação de leitores e uma carência de propostas de ensino que despertem o gosto pela leitura. De acordo com Dalvi (2011), as aulas de Língua Portuguesa não são atrativas e seus efeitos refletem os maus resultados do Brasil nos testes de leitura e escrita. De acordo com a autora, é necessário conhecer os alunos dos cursos de Letras, o que eles pensam e como são avaliados. São esses fatores que fomentam a melhora da qualidade da educação a ser ofertada, tanto em termos de escrita quanto, também, de leitura.

É importante apresentar o papel fundamental que a Literatura tem no desenvolvimento das crianças mesmo antes do período de alfabetização, uma vez que a relação do aluno com o universo simbólico não se dá apenas por uma via - a verbal (ORLANDI, 2006), mas também com outras formas de linguagem em sua relação com o mundo que as cercam. Paulo Freire (1982), em texto escrito no início desta década, lembranos muito bem a leitura da palavra e a leitura do mundo, entre a linguagem escrita e a realidade, entre o texto e o contexto. Referente ao ato de ler, não podemos conceber um ensino aprendizagem de alfabetização que forneça apenas meia leitura ao aluno.

Assim, alfabetizar uma criança é, entre outras coisas, ensiná-la a ler, a confrontar ou usar os textos escritos, compreendendo-os e situando-se melhor no mundo de acordo com os propósitos buscados nesses próprios textos (FREIRE, 1982). O educador deve ter o desenvolvimento do aluno em sua mente para formar novos leitores que não apenas decodifiquem as letras, mas desenvolvam estratégias que possibilitem chegar ao aprendizado com significado. Ensinar novos métodos é redirecionar os alunos para uma leitura mais organizada, o que faz com que não se compreenda apenas a diversidade dos textos, mas, a partir dessa leitura, levantem hipóteses. 
Uma criança tem a possibilidade de fazer várias atividades em relação a leitura: olhando figuras, relacionando-as com o que vê, respondendo e formulando perguntas etc. Dessa forma, tem uma noção de que o que está escrito é divertido e até agradável. Isso é saber ler. Solé (1998) afirma que é apenas por meio de uma abordagem mais ampla da leitura e da escrita que o docente conseguirá aproveitar da melhor forma os conhecimentos que o aluno já possui. Portanto, é preciso, também, que o professor leve em consideração as perguntas que os alunos fazem em sala, pois assim, poderá aumentar seus conhecimentos e utilizá-los em outras atividades, mais úteis e condizentes com a realidade do aluno. A aprendizagem da leitura na escola é de fundamental importância para integrar o aluno no mundo literário e, também, para formar o cidadão.

\section{CONSIDERAÇÕES FINAIS}

De acordo com o objetivo do presente trabalho, pudemos refletir sobre importância da leitura nos anos iniciais, e, também, os fatores que podem interferir na formação de leitores. É preciso descobrir o que é necessário para desenvolver e criar estratégias de leitura que podem ser utilizadas nos processos de aprendizagem, sendo o educador o mediador para essas estratégias serem alcançadas.

O ambiente escolar e as práticas do professor permitem, ao aluno, a plena aquisição da leitura, de forma eficiente, o que faz com que o espaço escolar se transforme num local de muitas experiências, onde o aluno constrói conhecimentos de leitura, conduzindo, para outros níveis, o processo de aprendizado. O hábito de ler exerce uma forte influência quanto ao desempenho escolar em várias áreas do conhecimento.

É muito proveitoso que os alunos sejam estimulados à prática da leitura, pois não é preciso grandes investimentos e está ao alcance de todos nas escolas, e mesmo com recursos reduzidos, poderá formar bons leitores. É preciso que a criança entre em contato cada vez mais cedo com livros infantis, histórias e o mundo da imaginação, pois, assim, melhor será o seu desenvolvimento. O seu despertar no mundo da escrita será mais rápido, podendo tornar-se, no futuro, um bom leitor e, também, uma pessoa 
mais reflexiva e criativa. Quando as atividades são significativas, a criança pode aprender com uma maior facilidade, principalmente quando envolvem o seu contexto de vida, o que faz com que se sinta parte integrante do processo de aprendizado. A leitura se torna uma importante ferramenta na formação dos sujeitos criativos e pensantes.

O hábito e o gosto pela leitura podem ser cultivados lá atrás, desde o nascimento da criança, devendo, depois, continuar na escola, e é função do professor proporcionar o devido incentivo a esse hábito. Na educação infantil e na alfabetização, a leitura tem um destaque muito grande, pois, nessa fase, a criança descobre o mundo das letras, e, nos anos iniciais, é preciso manter o hábito, promovendo momentos dedicados à leitura.

\section{REFERÊNCIAS}

BRASIL. Parâmetros curriculares nacionais. Brasília: MEC/SEF, 1997

Parâmetros curriculares nacionais. Brasília: MEC/SEF, 1998.

CANDIDO, A. O direito a literatura. In: CANDIDO, A. Vários escritos. São Paulo: Duas Cidades, 1995.

COSSON, R. Letramento literário: teoria e prática. São Paulo: Contexto, 2006.

DALVI, M. A. O Modernismo nos livros didáticos de ensino médio: os temas e textos tidos como fundadores e a formação do leitor escolarizado. Educação: Teoria e Prática, v. 21, n. 37, p. 38, 2011.

FREIRE, P. Ação Cultural para a Liberdade e outros escritos. $6^{\underline{a}}$ ed. Rio de Janeiro: Paz e Terra, 1982.

P. Pedagogia da autonomia. 9aㅡ ed. Rio de Janeiro: Paz e Terra, 1998.

KLEIMAM, A. Oficina de leitura: teoria \& prática. $5^{\underline{a}}$ ed. Campinas, SP: Pontes, Editora da Universidade Estadual de Campinas, 1997. 
LAJOLO, M. Meus alunos não gostam de ler... O que eu faço? Campinas: Unicamp/Cefiel/MEC, 2005.

MAIA, J. Literatura na formação de leitores e professores. São Paulo: Paulinas, 2007.

MARTINS, M. H. O que é leitura. 19a ed. São Paulo: Brasiliense, 1994.

OLIVEIRA, A. A. O professor mediador das leituras literárias. In: PAIVA, A.; MACIEL, F.; COSSON, R (Orgs). Literatura: ensino fundamental. Vol. 20. Brasília: Ministério da Educação, Secretaria de Educação Básica, 2010.

ORLANDI, E. (org). Introdução às ciências da linguagem: discurso e textualidade. Campinas, SP: Pontes Editores, 2006.

SOLÉ, I. Estratégias de leitura. $6^{\mathrm{a}}$ ed. Porto Alegre: Artmed, 1998.

Enviado: Abril, 2020.

Aprovado: Agosto, 2020. 